\title{
Lipoprotein p37 from Mycoplasma hyorhinis inhibiting mammalian cell adhesion
}

\author{
Wen-Bin Liu $^{\dagger}$, Jian-Zhi Zhang ${ }^{\dagger}$, Bei-Hai Jiang, Ting-Ting Ren, Man-Man Gong, Lin \\ Meng \& Cheng-Chao Shou* \\ Peking University School of Oncology and Beijing Institute for Cancer Research, Beijing 100034, People's \\ Republic of China
}

Received 15 June 2005; accepted 18 October 2005

(C) 2005 National Science Council, Taipei

Key words: cell adhesion, Golgi apparatus, Mycoplasma hyorhinis, p37 protein

\begin{abstract}
Summary
p37 protein is a membrane lipoprotein of Mycoplasma hyorhinis, and our previous work showed that there was high ratio of $M$. hyorhinis infection in human gastric carcinoma. To investigate the possible functions of p37 in cancer development, the nucleotide sequence of $p 37$ gene was modified and expressed well in transfected cells. We found that p37 localized at the Golgi apparatus and could be secreted out of the cell. Human gastric cancer cells AGS, after being transfected with the $p 37$ gene, were smaller, more spherical and easy to detach from each other. Their adhesion to matrix was also diminished and cytoskeleton in these stable $p 37$ AGS cell was rearranged and transcription co-factor $\beta$-actin was transferred to nucleolus with down-regulation of ICAM- 1 and integrin $\beta 1$. These findings will be helpful for us to elucidate the effects of p37 on eukaryotic cells as well as to better understand the potential relationship between cancer and mycoplasma infection.
\end{abstract}

\section{Introduction}

Mycoplasma is Gram-positive bacterium without a cell wall. Mycoplasma has been associated with many human diseases, such as pneumonitis and urinogenital infections [1-3]. Association between mycoplasma, carcinogenesis and metastasis has generally been supported although the underlying mechanism(s) remain an enigma [4-8]. Infectionrelated carcinogenesis, however, has been clearly documented with Helicobacter pylori, bacterium known to induce gastric cancer [9-10].

p37, a part of homologous high-affinity transport system in Mycoplasma hyorhinis [4, 11], is known to enhance the invasiveness of melanoma (C8161 and $\mathrm{A} 375 \mathrm{M})$ and prostate carcinoma (PC3 and Du-145) [6, 12]. The colony-forming abilities

\footnotetext{
*To whom correspondence should be addresse. Fax: + 86-1066175832; E-mail: cshou@vip.sina.com

$\uparrow$ These authors contributed equally to the work
}

of AGS and HEK 293T cells are greatly improved by p37 (unpublished data); however, the precise mechanism is still unknown.

In this study, we re-designed the $p 37$ nucleotide sequence and expressed the protein p37 in eukaryotic cells. Then we characterized its sorting and localization within the cells, as well as its secretion status. And finally, we investigated the effects of p37 on cell adhesion, which is closely related to invasiveness and metastasis of carcinoma cells, and its potential molecular mechanism was also studied.

\section{Materials and methods \\ Cell culture and bacterial strains}

COS-7, HeLa and HEK 293T cells were grown in Dulbecco's Modified Eagle Medium (DMEM) with $10 \%$ fetal calf serum (FCS). Mouse fibroblast 
cell line $\mathrm{C} 3 \mathrm{H} / 10 \mathrm{~T} 1 / 2(\mathrm{C} 3 \mathrm{H})$ was maintained in RPMI 1640 medium with 15\% FCS. Murine myeloid cell line 32D was maintained in RPMI 1640 culture medium containing $15 \%$ FCS and 5\% WEHI-3B conditioned medium. Human gastric cancer cells AGS were grown in F-12 nutrient medium with $10 \%$ FCS.

\section{Antibodies and reagents}

PD4, a mouse monoclonal antibody against p37, was prepared in our laboratory. Anti-ICAM-1, anti-integrin- $\alpha 1$, anti-integrin- $\beta 1$, anti- $\alpha$-tubulin and horseradish peroxidase (HRP)-conjugated goat anti-rabbit or mouse antibodies were purchased from Santa Cruz Biotechnology, Inc. (Santa Cruz, CA, USA). Anti- $\beta$-actin was purchased from Sigma (St. Louis, MO, USA). Protein A-agarose beads were purchased from Amersham Biosciences, UK Limited (Buchinghamshire, England). Lipofectamine 2000 was purchased from Invitrogen Life Technologies (Carlsbad, CA, USA). Human fibronectin was purchased from Haematologic technologies Inc. (Essex Junction, VT, USA) and polylysine was purchased from Beijing Zhongshan Biotechnology Co. (Beijing, China).

\section{Plasmid construction}

Eukaryotic expression plasmids pEGFP-C1, pEGFP-N1 and pcDNA3 were purchased from BD Biosciences, Clontech (Palo Alto, CA, USA). pcDNA3-RFP was developed in our laboratory. pGEM-T easy vector was purchased from Promega Corporation (Madison, MI, USA). The prokaryotic nucleotide sequence of p37 was changed into the sequence corresponding to eukaryotic codon-usage preference, with the ratio of A, G, T, C estimated and optimally adjusted. The nucleotide sequence of the designed p37 was chemically synthesized (by Shanghai Songong, China) and cloned into pcDNA3 vector to generate the recombinant vector pcDNA3-p37. This sequence of $p 37$, adapted to eukaryotic systems, was amplified using PCR and Platinum Taq DNApolymerase (Invitrogen). The forward and reverse primer were 5'-TAC TCG AGT CGC CAC CAT GGT GAA GAA G-3' and 5'-TTC CCG GGA CTT GAT GGC CTT CTC GTA C$3^{\prime}$, respectively. The PCR product was ligated into
pGEM-T easy vector to generate pGEM-T-p37, which was digested with Xho I and Xma I and then ligated into pEGFP-N1 vector to generate pEGFP-N1-p37. The nucleotide sequence of the p37 gene was digested with BamH I and EcoR I; resulting fragment was ligated to pEGFP-C1 vector to generate pEGFP-C1-p37 for transfection into COS-7, HeLa or HEK 293 T cells. From the transfected cells, total RNA and protein were extracted for further analysis. Total RNAs were extracted from $\mathrm{C} 3 \mathrm{H}$ and 32D cells using Trizol reagent (Invitrogen). RT-PCR was then manipulated using forward primer 5'-AAG CTT ATG AGG TTT CGT GAG CAG TTC-3' and reverse primer 5'-GGT ACC GGC AAC GAA GAC AAG TTG CTC-3' to amplify a $\beta 1$, 4-galactosyltransferase gene fragment, which was inserted into pcDNA3-RFP vector to generate p-GALAC-RFP with similar strategy as the construction of pEGFP-N1-p37 described above.

\section{Confocal microscopy}

COS-7 cells were seeded onto coverslips in six-well plates. When grown to $70-80 \%$ confluency, the cells were transfected with eukaryotic expression plasmid DNAs, pEGFP-C1, pEGFP-N1, pEGFPC1-p37, pEGFP-N1-p37 or p-GALAC-RFP, respectively as described above. Forty-eight hours later, the cells were washed with PBS and mounted onto glass slides with $60 \%$ glycerol. To observe the expression and localization of p37 in cells, TCS SP2 confocal laser scanning microscope (Leica, Germany) and Leica Confocal Software 2.00 Build 0585 were used to capture the images.

\section{Immunoprecipitation and western blot analysis}

COS-7 or HEK 293T cells were seeded in six-well plates and incubated at $37{ }^{\circ} \mathrm{C}$ in a humidified atmosphere of $5 \% \mathrm{CO}_{2}$. Cultures were transiently transfected with 1.0-1.5 $\mu \mathrm{g}$ DNAs (pEGFP-C1p37, pEGFP-N1-p37, pcDNA3-p37, pEGFP-C1, pEGFP-N1, or pcDNA3) using $15 \mu$ l Lipofectamine 2000 in $0.6 \mathrm{ml}$ of DMEM, in accordance with protocols recommended by the manufacturer. Three hours post-transfection, cells were incubated in fresh culture media for $48 \mathrm{~h}$. Cells were washed with phosphate-buffered saline (PBS), digested with trypsin and harvested by centrifugation. Cell pellets were lysed with ice-cold buffer $(\mathrm{pH} 7.4$, 
$50 \mathrm{mM}$ Tris- $\mathrm{Cl}, 300 \mathrm{mM} \mathrm{NaCl}, 5 \mathrm{mM}$ EDTA, $0.02 \% \mathrm{NaN}_{3}, 1 \%$ Triton X-100, $1 \mathrm{mM}$ phenylmethyl sulfonyl fluoride, $10 \mu \mathrm{g} / \mathrm{ml}$ pepstatin, $10 \mu \mathrm{g} /$ $\mathrm{ml}$ leupeptin, $10 \mu \mathrm{g} / \mathrm{ml}$ aprotinin) at $4{ }^{\circ} \mathrm{C}$ for $30 \mathrm{~min}$, centrifuged at $16,000 \mathrm{~g}$ for another $30 \mathrm{~min}$ and debris was removed. Supernatant was pre-cleared with $20 \mu \mathrm{l}$ protein A-agarose beads with shaking at $4{ }^{\circ} \mathrm{C}$ for $1 \mathrm{~h}$. After the centrifugation at $400 \mathrm{~g}$ for $2 \mathrm{~min}$, the pre-cleared supernatant was subsequently incubated with $4 \mu \mathrm{g}$ PD4 or normal mouse $\mathrm{IgG}$ at $4{ }^{\circ} \mathrm{C}$ for $4 \mathrm{~h}$, followed by the addition of $40 \mu \mathrm{l}$ protein Aagarose beads then incubated for $4 \mathrm{~h}$ or overnight at $4{ }^{\circ} \mathrm{C}$. The beads were collected by centrifugation and were used as subject to SDS-PAGE and Western blot followed with PD4 as primary antibody and horseradish peroxidase-conjugated $\mathrm{IgG}$ as secondary antibody. The enhanced chemiluminesence (ECL) Western blotting analysis system (Amersham-Pharmacia, NJ) was employed in this experiment. Meanwhile, the secreted protein p37 in conditioned medium from transiently transfected cells was also analyzed with immunoprecipitation and Western blot as that described above.

\section{Establishment of stable cell lines}

Human gastric cell line AGS was cultured in F-12 nutrient medium with $10 \%$ FCS and was transfected with pcDNA3-p37 or pcDNA3 by Lipofectamine 2000 following the instruction of the manufacturers. The stably transfected clones were screened with G 418 at a concentration of $500 \mu \mathrm{g} /$ $\mathrm{ml}$ and the single clone (AGS-p37 or AGS-Vector) was identified with RT-PCR and Western blot, respectively.

\section{Immunofluorescence}

AGS-p37 or AGS-Vector cells were seeded onto coverslips in six-well plates and cultured in F-12 nutrient medium for $24 \mathrm{~h}$. After washed with PBS, the cells were fixed in ice-cold methanol: acetone $(1: 1)$ for $20 \mathrm{~min}$ and blocked with $1 \%$ BSA for $30 \mathrm{~min}$ at room temperature. Then the cells were incubated with mouse anti- $\beta$-actin antibody at $37^{\circ} \mathrm{C}$ for $1 \mathrm{~h}$. Following wash with PBS and block with normal goat serum for $30 \mathrm{~min}$ at room temperature, TRITC-conjugated goat anti-mouse $\operatorname{IgG}$ was added and incubated for $1 \mathrm{~h}$ at $37^{\circ} \mathrm{C}$. Finally, the cells were observed under confocal microscope after washing and mounting.

\section{Cell adhesion assay}

AGS cells $\left(1 \times 10^{5}\right.$, AGS-p37 or AGS-Vector) were seeded in six-well plate in F-12 nutrient medium with $10 \%$ FCS. After $3 \mathrm{~h}$, cells were washed with PBS, digested with trypsin and counted with globulimeter. In the experiments without FCS in medium, human fibronectin or polylysine $(2 \mu \mathrm{g} /$ $\mathrm{ml}, 10 \mu \mathrm{g} / \mathrm{ml}$ or $50 \mu \mathrm{g} / \mathrm{ml}$ ) were covered on sixwell plates first and $1 \times 10^{5}$ AGS cells were seeded in F-12 nutrient medium. Or $1 \times 10^{5}$ AGS cells were seeded first and cultured in F-12 nutrient medium containing different concentrations of $\mathrm{CaCl}_{2}\left(10^{-5} \mathrm{mM}, 10^{-4} \mathrm{mM}\right.$ and $\left.10^{-3} \mathrm{mM}\right)$ or ethylene diamine tetraacetic acid (EDTA) $\left(10^{-6} \mathrm{mM}\right.$, $10^{-5} \mathrm{mM}$ and $10^{-4} \mathrm{mM}$ ), respectively. The counting procedures were the same as the above.

\section{Results}

Sequence mutation of the p37 gene

In order to study the function(s) of p37, previously we inserted its prokaryotic nucleotide sequence into the expression vectors pcDNA3 and pEGFPC1. Very low levels of p37 expression were detected in COS-7 and HEK 293T cells. The $M$. hyorhinis p37 gene is poorly expressed in eukaryotic cells due to preferential codon usage. Therefore, in order to study its function in infected cells, the p37-coding sequence was systematically altered, and the reconstructed sequence was chemically synthesized. The original sequence carries seven TGA triplets, which serve as codons for tryptophan in M. hyorhinis but as stop codons in eukaryotic cells. This triplets TGA was substituted with TGG in the newly-designed p37 coding sequence. This way, the sequence will be recognized and used as a tryptophan codon in the host cells. Furthermore, the Kozak consensus translation initiation sequence was added to the $5^{\prime}$ end, and TAA was chosen as the translation stop codon of the new construct. Thus the amino acid sequence of the reconstructed p37 is the same as that of the original mycoplasma membrane lipoprotein, with its entire amino acid sequence intact, 
1 CTACGGATCCTCGCCACC ATGG TGAAGAAGCTGAAGAAC TTCATCC TGT TCAGCAGCATC $\begin{array}{lllllllllllllll}M & L & K & K & \text { L } & \text { K } & \text { N } & \text { F } & \text { I } & \text { L } & \text { F } & \text { S } & \text { S } & \text { I }\end{array}$

61 T TCAGCCCCATCGCC TTCGCC ATCAGC TGCAGCAACACC GGCGTGGTGAAGCAGGAGGAC $\begin{array}{lllllllllllllllllllll}\mathrm{F} & \mathrm{S} & \mathrm{P} & \mathrm{I} & \mathrm{A} & \mathrm{F} & \mathrm{A} & \mathrm{I} & \mathrm{S} & \mathrm{C} & \mathrm{S} & \mathrm{N} & \mathrm{T} & \mathrm{G} & \mathrm{V} & \mathrm{V} & \mathrm{K} & \mathrm{Q} & \mathrm{E} & \mathrm{D}\end{array}$

121 GTGAGCGTGAGCCAGGGCCAGTGGGACAAGAGCATCACC T TCGGCGTGAGCGAGGCCTGG $\begin{array}{llllllllllllllllllll}V & S & V & S & Q & G & Q & \text { W } & \text { D } & \text { K } & \text { S } & \text { I } & \text { T } & \text { F } & \text { G } & \text { V } & \text { S } & \text { E } & \text { A } & \text { W }\end{array}$

181 CTGAACAAGAAGAAGGGCGGCGAGAAGGTGAACAAGGAGGTGATCAACACCTTCC TGGAG $\begin{array}{llllllllllllllllllll}\text { L } & \text { N } & \text { K } & \text { K } & \text { K } & \text { G } & \text { G } & \text { E } & \text { K } & \text { V } & \text { N } & \text { K } & \text { E } & \text { V } & \text { I } & \text { N } & \text { T } & \text { F } & \text { L } & \text { E }\end{array}$

241 AACTTCAAGA AGGAGTTCAACAAGCTGAAGAACGCCAACGACAAGACCAAGAAC TTCGAC $\begin{array}{lllllllllllllllllllll}\mathrm{N} & \mathrm{F} & \mathrm{K} & \mathrm{K} & \mathrm{E} & \mathrm{F} & \mathrm{N} & \mathrm{K} & \mathrm{L} & \mathrm{K} & \mathrm{N} & \mathrm{A} & \mathrm{N} & \mathrm{D} & \mathrm{K} & \mathrm{T} & \mathrm{K} & \mathrm{N} & \mathrm{F} & \mathrm{D}\end{array}$

301 GACGTGGACTTCAAGGTGAC CCCCATCCAGGAC TTCACCG TGC TGCTGAA CAACCTGAGC $\begin{array}{llllllllllllllllllll}\text { D } & \text { V } & \text { D } & \text { F } & \text { K } & \text { V } & \text { T } & \text { P } & \text { I } & \text { Q } & \text { D } & \text { F } & \text { T } & \text { V } & \text { F } & \text { F } & \text { N } & \text { N } & \text { L } & \text { S }\end{array}$

361 ACCGACAACCCC GAGCTGGACTTC GGCATC AACGCCAGCGGCAAGC TGGTGGAGTTCCTG $\begin{array}{llllllllllllllllllll}T & D & N & P & E & \text { L } & D & F & G & \text { I } & \text { N } & \text { A } & \text { S } & \text { G } & \text { K } & \text { L } & \text { V } & \text { E } & \text { F } & \text { L }\end{array}$

421 AAGAACAACCCC GGCATCAT CACCCCCGCC CTGGAGACCA CCACCAAGAGC TTCGTGTTC $\begin{array}{llllllllllllllllllll}\text { K } & \text { N } & \text { N } & \text { P } & \text { G } & \text { I } & \text { I } & \text { T } & \text { P } & \text { A } & \text { L } & \text { E } & \text { T } & \text { T } & \text { T } & \text { N } & \text { S } & \text { F } & \text { V } & \text { F }\end{array}$

481 GACAAGGAGAAGGACAAG TTC TACGTGGACGGCACCGAC AGCGACCCCCTGGTGAAGATC $\begin{array}{llllllllllllllllllll}D & K & E & K & D & K & F & \text { Y } & \text { V } & \text { D } & \text { G } & \text { T } & \text { D } & \text { S } & \text { D } & \text { P } & \text { L } & \text { V } & \text { K } & \text { I }\end{array}$

541 GCCAAGGAGA TCAACAAGATCTTC GTGGAGACCCCC TACGCCAGCTGGACCGACGAGAAC $\begin{array}{lllllllllllllllllllll}\text { A } & \mathrm{K} & \mathrm{E} & \mathrm{I} & \mathrm{N} & \mathrm{K} & \mathrm{I} & \mathrm{F} & \mathrm{V} & \mathrm{E} & \mathrm{T} & \mathrm{P} & \mathrm{Y} & \mathrm{A} & \mathrm{S} & \mathrm{W} & \mathrm{T} & \mathrm{D} & \mathrm{E} & \mathrm{N}\end{array}$

601 CACAAGTGG A ACGGCAACGTGTAC CAGAGCGTGTACGACCCCACCGTGCA GGCCAACTTC $\begin{array}{llllllllllllllllllllll}H & \text { K } & \text { W } & \text { N } & G & N & V & Y & Q & \text { S } & \text { V } & \text { Y } & \text { D } & \text { P } & \text { T } & \text { V } & \text { Q } & \text { A } & \text { N } & \text { F }\end{array}$

661 TACAGAGGCATG ATCTGG ATCAAGGGCAACGACGAGACCC TGGCCAAGATCAAGAAGGCC

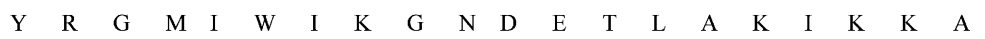

721 TGGAACGACA AGGACTGGAACACCTTCAGA AACTTC GGCATCCTGCACGGCAAGGACAAC

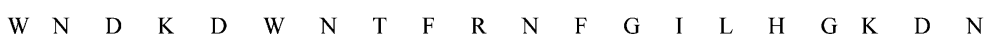

781 AGCTTCAGCAAGTTCAAGCTGGAGGAGACC ATCCTGAAGA ACCAC TTC CAGAACAAG TTC $\begin{array}{llllllllllllllllllll}S & \mathrm{~F} & \mathrm{~S} & \mathrm{~K} & \mathrm{~F} & \mathrm{~K} & \mathrm{~L} & \mathrm{E} & \mathrm{E} & \mathrm{T} & \mathrm{I} & \mathrm{L} & \mathrm{K} & \mathrm{N} & \mathrm{H} & \mathrm{F} & \mathrm{Q} & \mathrm{N} & \mathrm{K} & \mathrm{F}\end{array}$

841 ACCACCCTGAACGAGGACAGAAGCGCCCACCCCAACGCCT ACAAGCAGAAGAGCGCCGAC $\begin{array}{lllllllllllllllllllll}\mathrm{T} & \mathrm{T} & \mathrm{L} & \mathrm{N} & \mathrm{E} & \mathrm{D} & \mathrm{R} & \mathrm{S} & \mathrm{A} & \mathrm{H} & \mathrm{P} & \mathrm{N} & \mathrm{A} & \mathrm{Y} & \mathrm{K} & \mathrm{Q} & \mathrm{K} & \mathrm{S} & \mathrm{A} & \mathrm{D}\end{array}$

901 ACCCTGGGCACCCTGGACGACTTCCACATC GCCT TCAGCG AGGAGGGCAGC TTCGCC TGG $\begin{array}{llllllllllllllllllllllllllllllll}T & \text { L } & G & \text { T } & \text { L } & \text { D } & \text { D } & \text { F } & \text { H } & \text { I } & \text { A } & \text { F } & \text { S } & \text { E } & \text { E } & \text { G } & \text { S } & \text { F } & \text { A } & \text { W }\end{array}$

961 ACCCACAACA AGAGCGCCAC CAAGCCCTT GAG ACCAAG GCC AACGAGAAGATGGAGGCC $\begin{array}{llllllllllllllllllllll}\mathrm{T} & \mathrm{H} & \mathrm{N} & \mathrm{K} & \mathrm{S} & \mathrm{A} & \mathrm{T} & \mathrm{K} & \mathrm{P} & \mathrm{F} & \mathrm{E} & \mathrm{T} & \mathrm{K} & \mathrm{A} & \mathrm{N} & \mathrm{E} & \mathrm{K} & \mathrm{M} & \mathrm{E} & \mathrm{A}\end{array}$

1021 CTGATCGTGA CCAACCCCAT CCCCTAC GACGTG GGCGTGT TCAGAAAGAG CGTGAACCAG $\begin{array}{llllllllllllllllllll}\text { L } & \text { I } & \text { V } & \text { T } & \text { N } & \text { P } & \text { I } & \text { P } & \text { Y } & \text { D } & \text { V } & \text { G } & \text { V } & \text { F } & \text { R } & \text { K } & \text { S } & \text { V } & \text { N } & Q\end{array}$

1081 CTGGAGCAGA ACCTGATCGT GCAGACC TTCATCAACCTGGCCAAGAACAA GCAGGACACC $\begin{array}{llllllllllllllllllllll}\mathrm{L} & \mathrm{E} & \mathrm{Q} & \mathrm{N} & \mathrm{L} & \mathrm{I} & \mathrm{V} & \mathrm{Q} & \mathrm{T} & \mathrm{F} & \mathrm{I} & \mathrm{N} & \mathrm{L} & \mathrm{A} & \mathrm{K} & \mathrm{N} & \mathrm{K} & \mathrm{Q} & \mathrm{D} & \mathrm{T}\end{array}$

1141 TAC GGCCCCC TGCTGGGC TA CAACGGCTACAAGAAGATCG ACAACTTCCA GAAGGAGATC

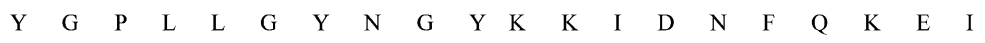

1201 GTGGAGGTGTAC GAGAAGGCC ATCAAGTAA GAATTCATCC

$\begin{array}{lllllllll}V & E & V & Y & E & K & A & I & K\end{array}$

Figure 1. Eukaryotic predisposed nucleotide sequence of $p 37$ gene. The Kozak sequence, stop codon and mutant TGG codons are indicated in bold and underlined. The full length of reading frame is $1209 \mathrm{bp}$, which encodes 403 amino acids.

including that of $\mathrm{N}$-terminal cell membrane localization signal peptide ( 23 amino acids). The reconstituted p37 coding sequence shown in Figure 1 was cloned into a pcDNA3 vector for expression in eukaryotic cells.

\section{Expression, secretion and localization of p37 in eukaryotic cells}

The pcDNA3 vector carrying the reconstituted p37 coding sequence was used to transfect COS-7 
(a)

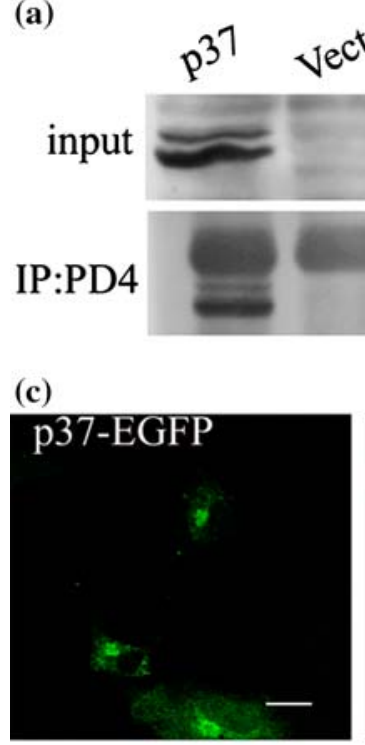

(b)

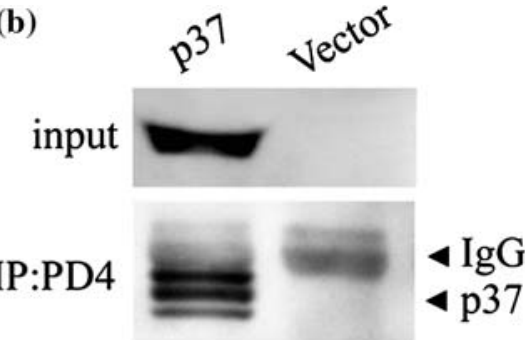

(d)
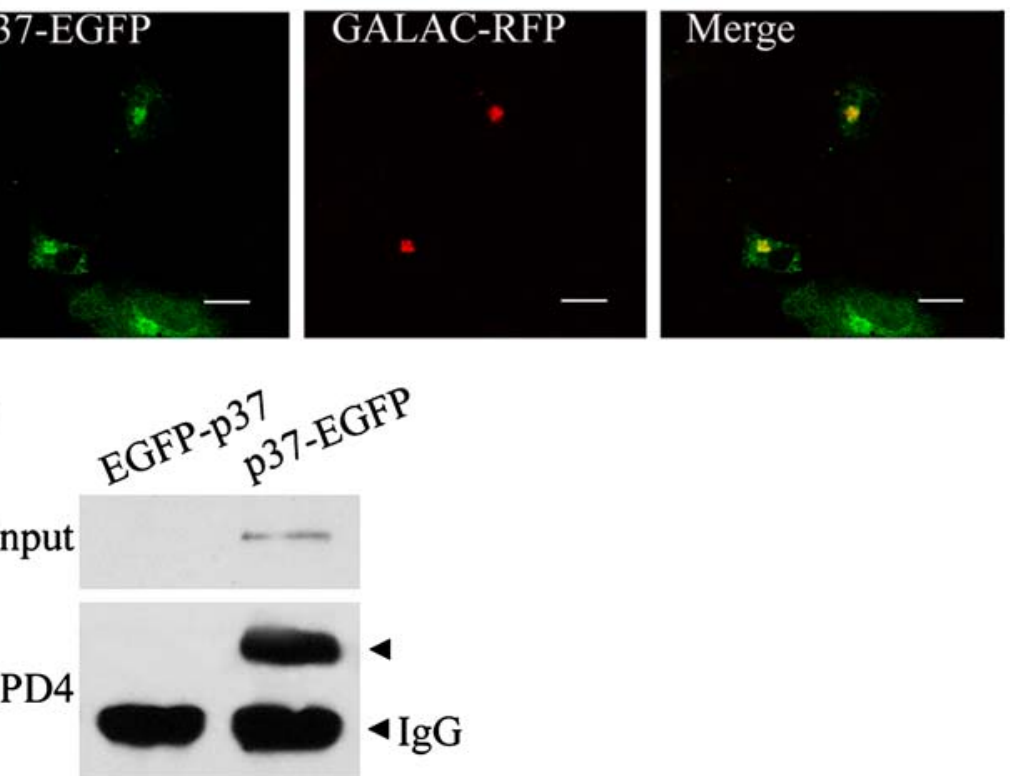

Figure 2. Expression, secretion and localization of p37 protein. (a) COS-7 cells were transfected with pcDNA3-p37 and the expressed p37 was immunoprecipitated by mouse monoclonal antibody PD4, separated in 10\% SDS PAGE and monitored by ECL Western blot. PD4 was used as primary antibody. (b) Detection of p37 protein in conditioned medium. (c) COS-7 cells were co-transfected with pEGFP-N1-p37 and p-GALAC-RFP and the localization of p37 in the cells was observed with confocal microscopy. Scale bars represent $20 \mu \mathrm{m}$. (d) Fusion protein p37-EGFP or EGFP-p37 was detected in conditioned medium from COS-7 cells transfected with pEGFP-N1-p37 or pEGFP-C1-p37, the upper arrow means p37 in fusion proteins. All data above are representative of two or more independent experiments.

and HEK 293T cells. In both cases, intracellular expression of p37 was observed by ECL Western blot (Figure 2a). Additionally, p37 was secreted into the conditioned medium, as shown in Figure $2 \mathrm{~b}$. There were three protein bands with mass weights lower than that of $\operatorname{IgG}$ and that represented three types of p37 as precursor, intermediate and mature types (unpublished data). The reconstructed p37 coding sequence was inserted into pEGFP-N1 and pEGFP-C1 to generate chimeric proteins $\mathrm{p} 37$-EGFP or EGFP-p37 in COS-7 and HEK 293T cells. $\beta 1$, 4-galactosyltransferase (GALAC) was used since it is known to sort only to the Golgi apparatus; its sorting signal peptide fragment was fused with red fluorescence protein (RFP), forming the chimeric GALACRFP as a Golgi marker [13]. Results showed that while EGFP protein was diffuse in all of the cells, p37 was present exclusively in Golgi apparatus at expression early stage and mainly in Golgi at expression late stage (Figure 2c), which meant that p37 localized to the Golgi. Data also indicated that fusion protein $\mathrm{p} 37$-EGFP could be secreted into the supernatant, but not EGFP-p37 (Figure 2d).

p37-transfected AGS cells are smaller, more spherical and detach easily

Whether p37 is intracellular or extracellular, it can affect the physiological function of the cell. Using 

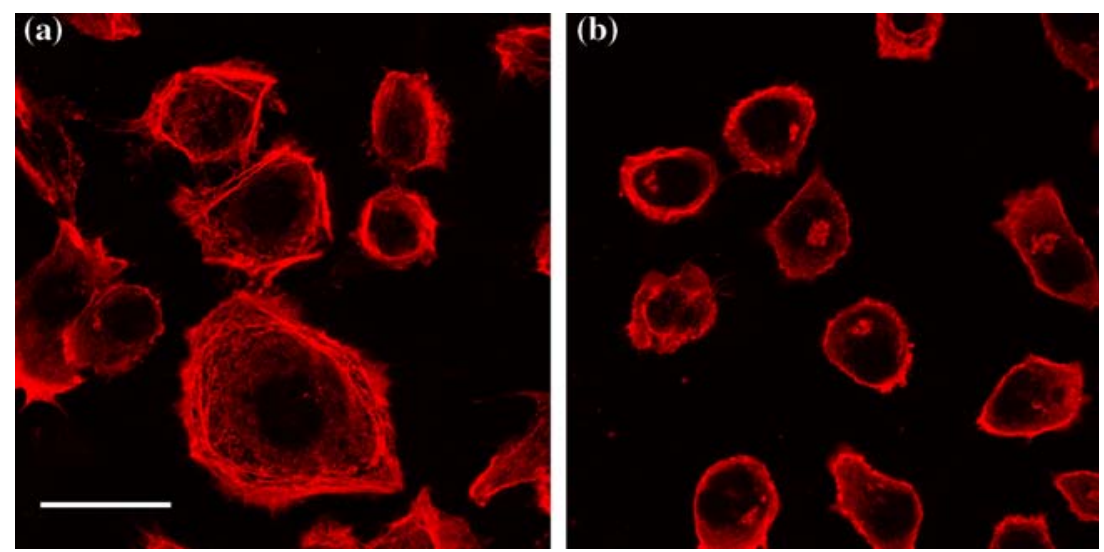

Figure 3. Morphological change of AGS cells transfected by $p 37$ gene. AGS cells transfected by vector are shown in (a), and that transfected with $p 37$ are shown in (b). All data represent three independent experiments. Scale bar represents $20 \mu \mathrm{m}$.

(a)
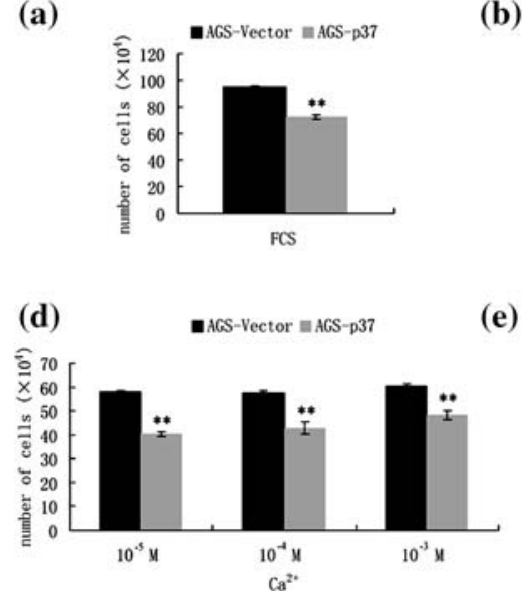

(b)

(e)
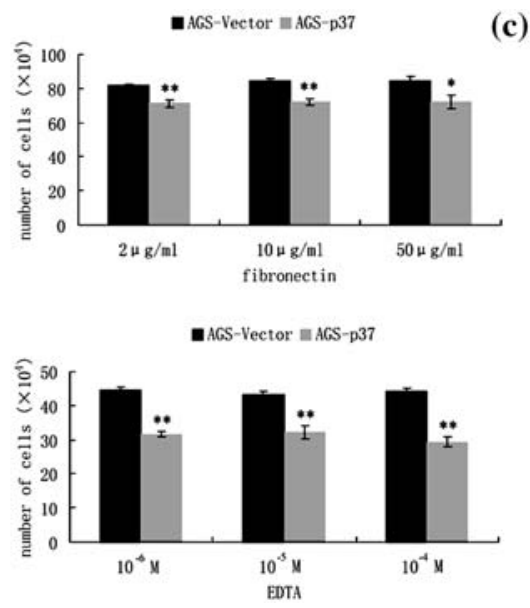

(c)

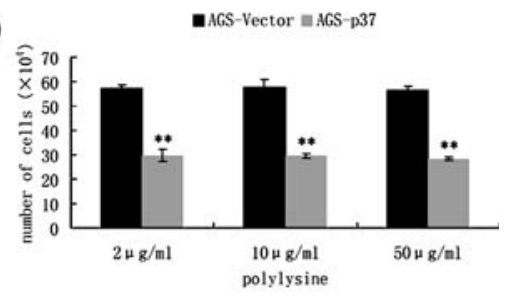

Figure 4. Cell adhesion analysis. AGS-Vector and AGS-p37 cells were seeded in six-well plates in F-12 nutrient medium with $10 \%$ fetal calf serum (FCS) (a), fibronectin-coated plate without FCS (b), polylysine-coated plate without FCS (c), medium with $\mathrm{CaCl}_{2}$ $\left(\mathrm{Ca}^{2+}\right)$ and without FCS (d) and medium with EDTA and without FCS (e). All data represent three independent experiments.

immunofluorescence, it was noted that the p37 stably transfected AGS cells (AGS-p37) were smaller than the control AGS cells (AGS-Vector). Additionally, the AGS-p37 cells were easier to detach from one another and became more spherical after fixation with paraformaldehyde or methanol and acetone (Figure 3).

\section{p37 inhibiting cell adhesion}

As shown in Figure 4a, there were more AGSVector cells than AGS-p37 cells attached to the plate. And it is easier for AGS to attach to the plate in serum and appeared to be obtuse fusiformate. And there were more AGS-Vector cells on fibronectin-coated or polylysine-coated plates (Figure 4b, c). On fibronectin-coated plate, AGSp37 cells appeared to be sharp fusiformate while AGS-Vector cells appeared to be obtuse fusiformate (data not shown). $\mathrm{Ca}^{2+}$ can promote cell adhesion while EDTA can inhibit cell adhesion $[14,15]$. In spite of treating with $\mathrm{CaCl}_{2}$ or EDTA, AGS-p37 cells attaching to the plate were less than AGS-Vector cells (Figure 4d, e).

\section{Cytoskeleton is rearranged}

As shown in Figure 3, cytoskeleton in AGSp37 cell was disturbed and rearranged, the long and straight $\beta$-actin microfilaments were not 


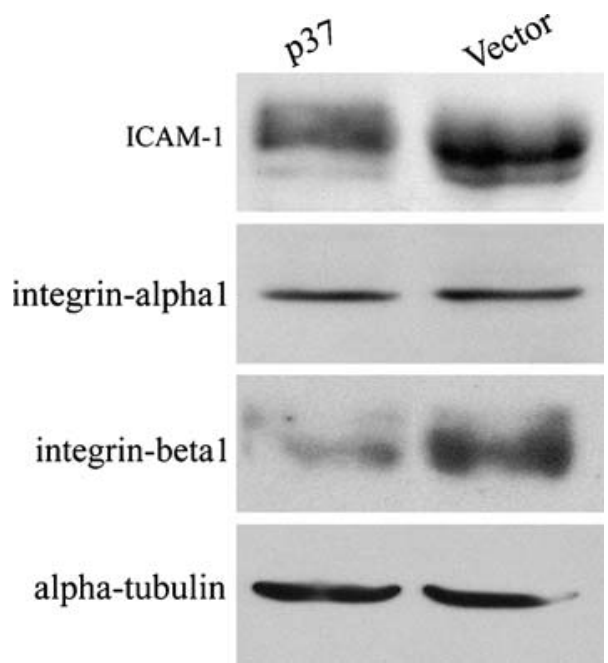

Figure 5. Expression analysis of adhesion molecules in AGS cells transfected with p37 gene. Intercellular adhesion molecule-1 (ICAM-1) and integrin beta 1 were down-regulated in AGS-p37 cell line and expression level of integrin alpha 1 was not changed. All data are representative of three independent experiments.

observed and the presence of $\beta$-actin became denser and it was transferred to nucleolus.

\section{ICAM-1 and integrin $\beta 1$ were down-regulated}

Results also indicated that expressions of the intercellular adhesion molecule 1 (ICAM-1) and integrin $\beta 1$ were down-regulated in AGS-p37 cell. Expression change of integrin $\alpha 1$ was not observed (Figure 5).

\section{Discussion}

We have substituted specific codons of $p 37$ so that the designed mycoplasmal gene could be expressed well in cultured eukaryotic cells without altering the composition and sequence of the resultant protein. It is a beneficial way to express the mycoplasmal genes in eukaryotic cells that use TGA codon for tryptophan rather than for a stop codon.

During our transfection experiments, we followed the fate of p37 and found its appearing in both Golgi apparatus and conditioned medium, in HEK 293T, COS-7 and AGS cells, respectively. A signal peptide, 23 amino acids in length, is present at the $\mathrm{N}$-terminal of $\mathrm{p} 37$. These amino acids direct p37 to the cell outer membrane of $M$. hyorhinis [4] and p37 is exposed to host proteins when the bacterium infects eukaryotic cells. The signal peptide may guide the exportation of $\mathrm{p} 37$ protein from the host eukaryotic cells. However, whether or not there is another signal peptide that directs p37 to the Golgi apparatus remains uncertain. Although no such peptide is known to exist update, presence of different localization peptides is well identified, such as KDEL for localization at the endoplasmic reticulum [16] and NLS for localization at the nucleus [17]. There are different possibilities resulting in protein $\mathrm{p} 37$ localization at the Golgi apparatus such as folding problem and its high expression in the transfected cells as an exogenic protein that may be trapped by proteins localized at the apparatus, or its physiological reaction with some unknown proteins at the Golgi apparatus.

The $p 37$ stably transfected AGS cell line became smaller, more spherical, and easier to detach from one another and matrix; possibly this was due to down-regulation of ICAM-1 and integrin $\beta 1$. ICAM-1 plays an important role in cell adhesion to the vascular endothelium and may have a role in tumor cell dissemination or metastasis [18, 19]. Suppressed expression of VCAM- 1 and ICAM- 1 is associated with reduced adhesion of monocytes and lymphocytes to human umbilical vein endothelial cell stimulated by cytokine [20]. ICAM-1 plays a crucial role in Trypanosoma cruzi recruitment to the cardiac tissue and host susceptibility during $T$. cruzi infection [21]. Integrin $\beta 1$-mediated cell adhesion regulates a multitude of cellular responses, including proliferation, survival and cross-talk between different cellular signaling pathways. A collagen-binding integrin $\alpha 1 \beta 1$ functions as a negative regulator of epidermal growth factor receptor (EGFR) signaling through the activation of a protein tyrosine phosphatase [22, 23]. Integrinmediated cell-ECM interactions play a critical role in cell adhesion, migration and morphogenesis during vertebrate retinal development [24]. We could not detect the expression of integrin $\beta 2$, a receptor of ICAM-1, in AGS cell. There is lipid(s) attached to a cysteine at the N-terminal of p37 protein and it is complex and affects the function of p37 (unpublished data). Possibly the lipid interferes the phospholipids domain on cell membrane and affects cell adhesion.

We also performed cDNA microarray to analyze the gene expression profile of AGS cells. Comparing to control cells, in AGS-p37 cells, the 
transcriptions of cadherin 10 , selectin $\mathrm{P}$ and actinin $\alpha 4$ were down-regulated, but the mRNA of epithelial growth factor receptor (EGFR) was up-regulated (unpublished data). And these may contribute to decreased cell adhesion.

We found that the $\beta$-actin was transferred to nucleolus in AGS-p37 cell. That indicated that expression of certain target genes were regulated because $\beta$-actin is a co-factor of RNA polymerase II in gene transcription $[25,26]$. Actin is abundant in the nucleus and has been implicated in transcription [25] and RNA polymerase II is present in the nucleolus-like body at all transcriptional states of the oocyte nucleus [27]. Actin and RNA polymerase II co-localize in nucleus [25, 28]. Possibly when the expression of some genes, such as ICAM- 1 and integrin $\beta 1$ is changed, the $\beta$-actin and RNA polymerase II are recruited and transferred to nucleolus.

By method of yeast two-hybrid, we found that p37 protein bound NORPEG (novel retinal pigment epithelial cell gene) [29], which is a cytoskeleton-related protein containing six ankyrin repeats and a long coiled-coil domain that are involved in protein-protein interactions. The ankyrin anchors the cytoskeleton to erythrocyte membrane and the NORPEG protein appears to be a cytoskeleton protein [30], so when p37 protein is expressed in cell, it interacts with NORPEG and other proteins and affects the cytoskeleton assembly. The cytoskeleton is then rearranged and $\beta$-actin is transferred to nucleolus to help expression of target genes resulting in decreased cell adhesion.

Our previous works showed that there were Mycoplasma hyorhinis infection in gastric cancer tissues [31], which suggested there was possible relationship between cancer development and mycoplasma infection. Because p37 is a major antigen protein and part of a homologous highaffinity transport system in Mycoplasma hyorhinis, our results in this study will lend us further understanding of the special characteristics and function of p37 protein in diseases involved by mycoplasma infection.

\section{Acknowledgements}

This work is supported by the National Natural Science Foundation of China (Grant No. 30130190), the Beijing Natural Science Foundation
(Grant No. 7012007), and National "211 Project" of Peking University and Peking University Cancer Center.We thank Dr. S.M. Zhang for providing a stock of $\mathrm{C} 3 \mathrm{H}, 32 \mathrm{D}$ and WEHI-3B cells, and P.C. Huang, Z.Q. Zhang, T.Q. Jin, H.T. Lei and $\mathrm{Q}$. Shao for their valuable suggestions.

\section{References}

1. Maltezou H.C., La-Scola B., Astra H., Constantopoulou I., Vlahou V., Kafetzis D.A., Constantopoulos A.G. and Raoult D., Mycoplasma pneumoniae and Legionella pneumophila in community-acquired lower respiratory tract infections among hospitalized children: diagnosis by real time PCR. Scand. J. Infect. Dis. 36: 639-642, 2004.

2. Timitilli A., Di Rocco M., Nattero G., Tacchella A. and Giacchino R., Unusual manifestations of infections due to Mycoplasma pneumoniae in children. Infez. Med. 12: 113117, 2004.

3. Jurstrand M., Jensen J.S., Fredlund H., Falk L. and Molling P., Detection of Mycoplasma genitalium in urogenital specimens by real-time PCR and by conventional PCR assay. J. Med. Microbiol. 54: 23-29, 2005.

4. Dudler R., Schmidhauser C., Parish R.W., Wettenhall R.E. and Schmidt T., A Mycoplasma high-affinity transport system and the in vitro invasiveness of mouse sarcoma cells. The EMBO J. 7: 3963-3970, 1988.

5. Feng S.H., Tsai S., Rodriguez J. and Lo S.C., Mycoplasmal infections prevent apoptosis and induce malignant transformation of interleukin-3-dependent 32D hematopoietic cells. Mol. Cell. Biol. 19: 7995-8002, 1999.

6. Reutzel R., Boehlein S.K., Govindasamy L., Brenes R.B., Agbandje-McKenna M., Schuster S.M. and McKenna R., Crystallization and preliminary X-ray analysis of the tumor metastasis factor p37. Acta Crystallogr. D. Biol. Crystallogr. 58: 2141-1144, 2002.

7. Schmidhauser C., Dudler R., Schmidt T. and Parish R.W., A mycoplasmal protein influences tumor cell invasiveness and contact inhibition in vitro. J. Cell Sci. 95: 499-506, 1990.

8. Tsai S., Wear D.J., Shih J.W. and Lo S.C., Mycoplasmas and oncogenesis: persistent infection and multistage malignant transformation. Proc. Natl. Acad. Sci. USA 92: 10197-10201, 1995

9. Correa P., Is gastric cancer preventable?. Gut 53: 12171219, 2004.

10. De Luca A. and Iaquinto G., Helicobacter pylori and gastric diseases: a dangerous association. Cancer Lett. 213: 1-10, 2004.

11. Ning J.Y., Sun G.X., Huang S., Ma H., An P., Meng L., Song S.M., Wu J. and Shou C.C., Identification of antigens by monoclonal antibody PD4 and its expression in Escherichia coli. World J. Gastroenterol. 9: 2164-2168, 2003.

12. Ketcham C.M., Anai S., Reutzel R., Sheng S., Schuster S.M., Brenes R.B., Agbandje-McKenna M., McKenna R., Rosser C.J. and Boehlein S.K., p37 induces tumor invasiveness. Mol Cancer Ther. 4: 1031-1038, 2005.

13. Russo R.N., Shaper N.L. and Shaper J.H., Bovine beta 1, 4-galactosyltransferase: two sets of mRNA transcripts 
encode two forms of the protein with different amino-terminal domains. In vitro translation experiments demonstrate that both the short and the long forms of the enzyme are type II membrane-bound glycoproteins. J. Biol. Chem. 265: 3324-3331, 1990.

14. Yang W., Wilkins A.L., Ye Y., Liu Z.R., Li S.Y., Urbauer J.L., Hellinga H.W., Kearney A., van der Merwe P.A. and Yang J.J., Design of a calcium-binding protein with desired structure in a cell adhesion molecule. J. Am. Chem. Soc. 127: 2085-2093, 2005

15. Odenthal U., Haehn S., Tunggal P., Merkl B., Schomburg D., Frie C., Paulsson M. and Smyth N., Molecular analysis of laminin N-terminal domains mediating self-interactions. J. Biol. Chem. 279: 44504-44512, 2004.

16. Le Bot N., Antony C., White J., Karsenti E. and Vernos I., Role of xklp3, a subunit of the Xenopus kinesin II heterotrimeric complex, in membrane transport between the endoplasmic reticulum and the Golgi apparatus. J. Cell Biol. 143: 1559-1573, 1998.

17. Myers J.M., Martins G.G., Ostrowski J. and Stachowiak M.K., Nuclear trafficking of FGFR1: a role for the transmembrane domain. J. Cell Biochem. 88: 1273-1291, 2003.

18. Finzel A.H., Reininger A.J., Bode P.A. and Wurzinger L.J., ICAM-1 supports adhesion of human small-cell lung carcinoma to endothelial cells. Clin. Exp. Metastasis. 21: 185-189, 2004.

19. O'Hanlon D.M., Fitzsimons H., Lynch J., Tormey S., Malone C. and Given H.F., Soluble adhesion molecules (E-selectin, ICAM-1 and VCAM-1) in breast carcinoma. Eur. J. Cancer. 38: 2252-2257, 2002.

20. Zapolska-Downar D., Siennicka A., Kaczmarczyk M., Kolodziej B. and Naruszewicz M., Butyrate inhibits cytokine-induced VCAM-1 and ICAM-1 expression in cultured endothelial cells: the role of NF-kappa B and PPAR alpha. J. Nutr. Biochem. 15: 220-228, 2004.

21. Michailowsky V., Celes M.R., Marino A.P., Silva A.A., Vieira L.Q., Rossi M.A., Gazzinelli R.T., Lannes-Vieira J. and Silva J.S., Intercellular adhesion molecule 1 deficiency leads to impaired recruitment of $\mathrm{T}$ lymphocytes and enhanced host susceptibility to infection with Trypanosoma cruzi. J. Immunol. 173: 463-470, 2004.
22. Defilippi P., Rosso A., Dentelli P., Calvi C., Garbarino G., Tarone G., Pegoraro L. and Brizzi M.F., Beta 1 integrin and IL-3R coordinately regulate STAT5 activation and anchorage-dependent proliferation. J. Cell Biol. 168: 1099-1108, 2005.

23. Mattila E., Pellinen T., Nevo J., Vuoriluoto K., Arjonen A. and Ivaska J., Negative regulation of EGFR signaling through integrin-alpha 1 beta 1-mediated activation of protein tyrosine phosphatase TCPTP. Nat. Cell Biol. 7: $78-85,2005$.

24. Li M. and Sakaguchi D.S., Inhibition of integrin-mediated adhesion and signaling disrupts retinal development. Dev. Biol. 275: 202-214, 2004.

25. Hofmann W.A., Stojiljkovic L., Fuchsova B., Vargas G.M., Mavrommatis E., Philimonenko V., Kysela K., Goodrich J.A., Lessard J.L., Hope T.J., Hozak P. and de Lanerolle P., Actin is part of pre-initiation complexes and is necessary for transcription by RNA polymerase II. Nat. Cell Biol. 6: 1094-1101, 2004

26. Franke W.W., Actin's many actions start at the genes. Nat. Cell Biol. 6: 1013-1014, 2004.

27. Parfenov V.N., Davis D.S., Pochukalina G.N., Kostyuchek D. and Murti K.G., Nuclear distribution of RNA polymerase II in human oocytes from antral follicles: dynamics relative to the transcriptional state and association with splicing factors. J. Cell Biochem. 77: 654-665, 2000.

28. Zhu X., Zeng X., Huang B. and Hao S., Actin is closely associated with RNA polymerase II and involved in activation of gene transcription. Biochem. Biophys. Res. Commun. 321: 623-630, 2004.

29. Sun Y.N., Jin G.L., Zhang J.Z., Wu J. and Shou C.C., Isolation and identification of a protein interacting with p37 protein of Mycoplasma hyorhinis. Prog. Biochem. Biophys. 31: 902-905, 2004(Chinese).

30. Kutty R.K., Kutty G., Samuel W., Duncan T., Bridges C.C., El-Sherbeeny A., Nagineni C.N., Smith S.B. and Wiggert B., Molecular characterization and developmental expression of NORPEG, a novel gene induced by retinoic acid. J. Biol. Chem. 276: 2831-2840, 2001.

31. Huang S., Li J.Y., Wu J., Meng L. and Shou C.C., Mycoplasma infection and different human carcinomas. World J. Gastroenterol. 7: 266-269, 2001. 